\title{
Correction to: The association between sonographic enthesitis and radiographic damage in psoriatic arthritis
}

\author{
Ari Polachek ${ }^{1,8}$, Richard Cook ${ }^{2}$, Vinod Chandran ${ }^{3,4,5}$, Dafna D. Gladman ${ }^{6}$ and Lihi Eder ${ }^{7 *}$
}

\section{Correction to: Arthritis Res Ther \\ https://doi.org/10.1186/s13075-017-1399-5}

Following publication of the original article [1], the authors reported an error in the affiliation of Ari Polachek. The correct affiliation of Dr. Polochek is:

${ }^{1}$ Centre for Prognostic Studies in the Rheumatic Diseases, Toronto Western Hospital, University of Toronto, 1-412, 399 Bathurst Street, Toronto, ON M5T 2S8, Canada.

${ }^{8}$ Department of Rheumatology, Tel Aviv Sourasky Medical Center, Sackler Faculty of Medicine, Tel Aviv University, Tel Aviv, Israel.

\begin{abstract}
Author details
${ }^{1}$ Centre for Prognostic Studies in the Rheumatic Diseases, Toronto Western Hospital, University of Toronto, 1-412, 399 Bathurst Street, Toronto, ON M5T 2S8, Canada. ${ }^{2}$ Department of Statistics and Actuarial Science, University of Waterloo, Waterloo, ON, Canada. ${ }^{3}$ Department of Medicine and Laboratory Medicine, Institute of Medical Science, University of Toronto, Toronto, ON, Canada. ${ }^{4}$ Department of Pathobiology, Institute of Medical Science,

University of Toronto, Toronto, ON, Canada. ${ }^{5}$ Centre for Prognosis Studies in the Rheumatic Diseases, Krembil Research Institute, Toronto Western Hospital, Toronto, ON, Canada. ${ }^{6}$ Center for Prognostic Studies in the Rheumatic Diseases, Toronto Western Hospital, University of Toronto, Toronto, ON, Canada. ${ }^{7}$ Department of Medicine, University of Toronto, Women's College Research Institute, Women's College Hospital, Room 6326, 76 Grenville Street, Toronto, ON M5S 1B2, Canada. ${ }^{8}$ Department of Rheumatology, Tel Aviv Sourasky Medical Center, Sackler Faculty of Medicine, Tel Aviv University, Tel Aviv, Israel.
\end{abstract}

Received: 3 January 2019 Accepted: 7 January 2019

Published online: 14 January 2019

\section{Reference}

1. Polachek, et al. The association between sonographic enthesitis and

radiographic damage in psoriatic arthritis. Arthritis Res Ther. 2017;19:189. https://doi.org/10.1186/s13075-017-1399-5.

\footnotetext{
* Correspondence: lihi.eder@wchospital.ca

${ }^{7}$ Department of Medicine, University of Toronto, Women's College Research Institute, Women's College Hospital, Room 6326, 76 Grenville Street, Toronto, ON M5S 1B2, Canada

Full list of author information is available at the end of the article
}

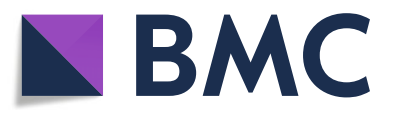

(c) The Author(s). 2019 Open Access This article is distributed under the terms of the Creative Commons Attribution 4.0 International License (http://creativecommons.org/licenses/by/4.0/), which permits unrestricted use, distribution, and reproduction in any medium, provided you give appropriate credit to the original author(s) and the source, provide a link to the Creative Commons license, and indicate if changes were made. The Creative Commons Public Domain Dedication waiver (http://creativecommons.org/publicdomain/zero/1.0/) applies to the data made available in this article, unless otherwise stated. 